\title{
Occurrence of spinal extradural arachnoid cysts in a child with concomitant intracranial midline abnormalities: case report
}

\author{
Jason A. Chen, PhD, ${ }^{1}$ Daniel Rosenthal Garber, MD, ${ }^{2}$ and Alan R. Cohen, MD $^{2}$ \\ 1Department of Neurosurgery, David Geffen School of Medicine, University of California, Los Angeles, California; and 'Division of \\ Pediatric Neurosurgery, Department of Neurosurgery, The Johns Hopkins University School of Medicine, Baltimore, Maryland \\ Spinal extradural arachnoid cysts (SEACs) are uncommon spinal lesions that may cause myelopathy, most frequently in \\ the 2 nd decade of life. There are multiple theories of their pathogenesis, and associated entities include spinal trauma, \\ spina bifida, and the lymphedema-distichiasis syndrome. The authors report the case of an otherwise healthy, develop- \\ mentally normal 13 -year-old boy who presented with multiple SEACs. Upon further neuroimaging workup, he was found \\ to have an asymptomatic retrocerebellar arachnoid cyst, cavum septi pellucidi, and cavum vergae. Three contiguous but \\ separate spinal cysts were identified intraoperatively, and they were completely excised with closure of the dural defects. \\ The patient recovered motor and sensory function of the lower extremities. This collection of uncommon neuroimaging \\ findings provides important clues to the pathogenesis of the disease and guides the optimal management of patients \\ with SEACs. The unusual presentation of SEACs, together with uncommon midline abnormalities, provides further evi- \\ dence of their congenital, midline origin. Therefore, it is reasonable to pursue imaging of the brain in atypical cases of \\ SEACS.
}

https://thejns.org/doi/abs/10.3171/2019.12.PEDS19108

KEYWORDS spinal extradural arachnoid cyst; meningeal cyst; retrocerebellar arachnoid cyst; cavum septi pellucidi; cavum vergae; midline abnormalities; spine; congenital

$\mathrm{S}$ PINAL extradural arachnoid cysts (SEACs) are uncommon fluid collections that may compress the spinal cord. Although extradural, these so-called "cysts" usually communicate with the subarachnoid space through a pedicle, suggesting that they are diverticula of the arachnoid through the dura. ${ }^{11}$ However, the initiating cause and the forces that lead to cyst enlargement are incompletely understood.

SEACs have a predilection for the dorsal thoracic spine and are most common between 11 and 15 years of age..$^{13}$ Although typically sporadic, SEACs have been associated with spinal trauma, prior neurosurgical procedures, ${ }^{15}$ arachnoiditis, ${ }^{38}$ neural tube defects, ${ }^{30}$ Scheuermann's kyphosis, ${ }^{8,29}$ and the lymphedema-distichiasis syndrome. ${ }^{3,533}$ In symptomatic patients, SEACs are typically excised and the pedicle ligated to prevent reaccumulation. ${ }^{32}$

We report the case of a child with multiple SEACs, found to have a retrocerebellar arachnoid cyst, cavum septi pellucidi, and cavum vergae. The co-occurrence of these abnormalities in a single patient tentatively suggests a common etiology and provides potential insight into the pathogenesis of each abnormality.

\section{Case Report}

History and Examination

A 13-year-old previously healthy boy presented with 10 days of bilateral lower-extremity paresthesias, originating at the thighs and spreading distally. Over the same time period, he developed bilateral leg weakness and had gait difficulty. There was no pain, sphincter dysfunction, antecedent trauma, or pertinent family history. On physical examination, he had diffuse hypertonia and hyperreflexia with four beats of ankle clonus bilaterally, a left Babinski sign, and a relative sensory level to pinprick at T10. There were no stigmata of syndromic associations, e.g., lymph-

ABBREVIATIONS SEAC $=$ spinal extradural arachnoid cyst.

SUBMITTED February 21, 2019. ACCEPTED December 30, 2019.

INCLUDE WHEN CITING Published online March 6, 2020; DOI: 10.3171/2019.12.PEDS19108. 


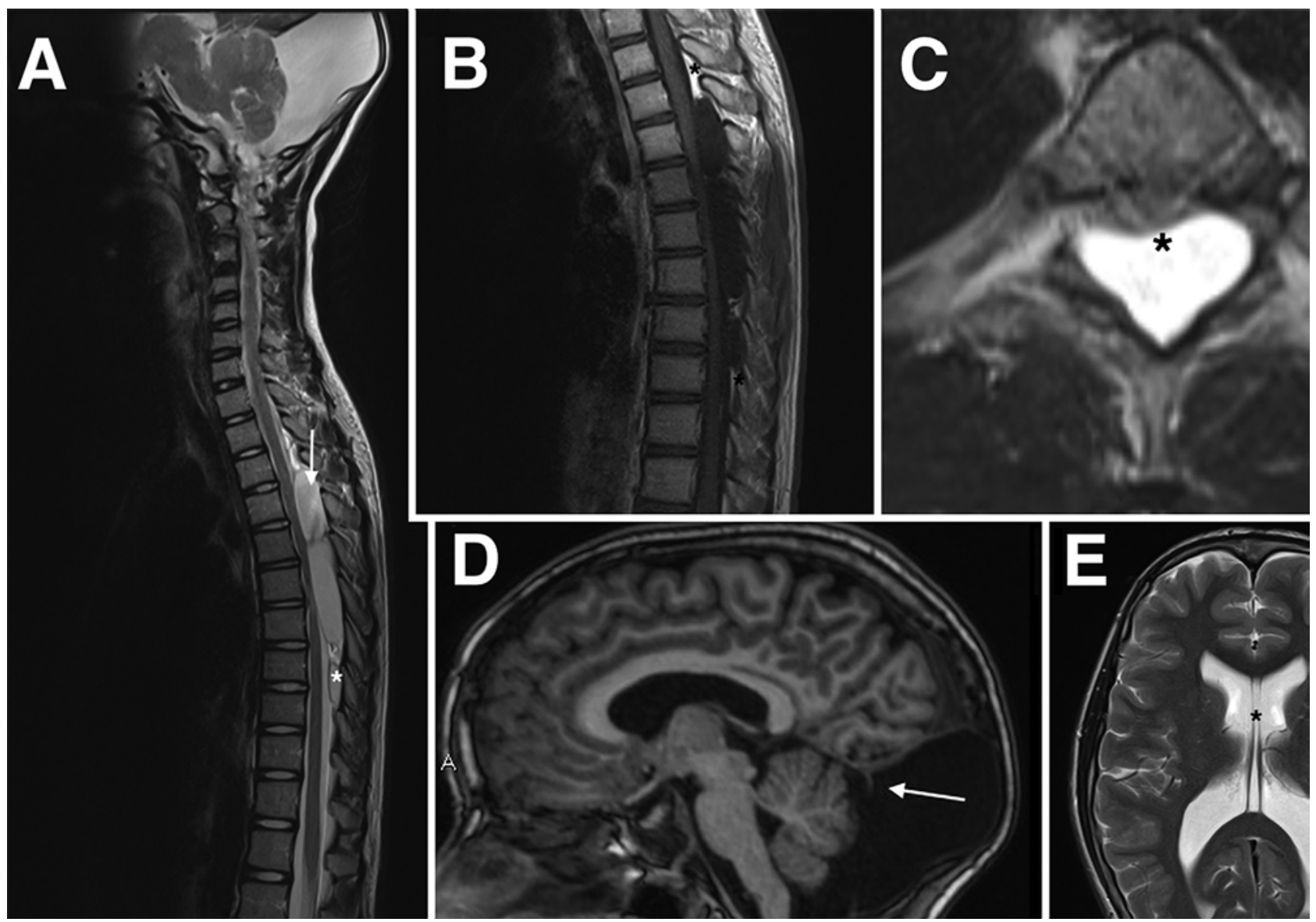

FIG. 1. Neuroimaging of the brain and spine at the time of presentation. A: Sagittal T2-weighted MR image of the thoracic spine demonstrates a multiloculated extradural fluid collection with a large cyst at T3-4 to T7-8 (arrow) and a small cyst at T8-9 (asterisk). B: Sagittal T1-weighted image highlights the obliteration of the posterior epidural fat by the cysts, resulting in characteristic "fat capping" at the superior and inferior poles (asterisks), clearly suggesting their extradural location. C: Axial T2-weighted section at the level of T4-5 exemplifies mass effect on the spinal cord by compression from the epidural arachnoid cyst (asterisk) posteriorly and associated widening of the neural foramina. D: Parasagittal T1-weighted image of the brain reveals a retrocerebellar cyst. A thick cyst wall is present (arrow). E: Axial T2-weighted section of the brain depicts the cavum vergae abnormality observed in the septum pellucidum (asterisk).

edema or supernumerary eyelashes (distichiasis). Workup for connective tissue disorders was unrevealing.

MRI of the brain, cervical spine, and thoracic spine was performed. In the spinal cord, two obvious cystic lesions were seen spanning T3-4 to T7-8 and T8-9, with significant mass effect on the thoracic spinal cord (Fig. 1A-C). The cysts eroded into surrounding bone and enlarged adjacent neural foramina. Obliteration of the epidural fat and fat capping at the superior and inferior poles emphasized their extradural location (Fig. 1B). In the brain, we appreciated a large retrocerebellar cyst and enlargement of the posterior fossa (Fig. 1D). There was moderate ventriculomegaly most prominent in the lateral ventricles. We also observed the cavum septi pellucidi and cavum vergae anomalies (Fig. 1E).

\section{Operation}

Laminotomy for pedicle ligation, cyst excision, and dural repair was performed. The incidental intracranial abnormalities were not symptomatic and thus were not treated. A midline skin incision was created between the T3 through T8 spinous processes, and the laminae were widely exposed. An osteoplastic laminectomy was performed from T4 through T8 bilaterally. Following removal of the bone flap, the cyst was visualized down to its inferior pole (with epidural fat capping; Fig. 2A).

The cyst was found to be thin-walled and tense (Fig. 2B). A septation ran through the center of the rostral cyst and a smaller daughter cyst was found buried in the epidural fat at the inferior pole, at the level of T8. Thus, in total, 3 cysts were identified: a rostral cyst, measuring 4.1 $\times 1.6 \times 0.3 \mathrm{~cm}$, with a pedicle at the T5 dorsal nerve root exit and dorsal midline; a midthoracic cyst, measuring 3.3 $\times 1.4 \times 0.2 \mathrm{~cm}$, with a pedicle at the T6 dorsal nerve root exit; and a caudal cyst, measuring $1.5 \times 1.3 \times 0.3 \mathrm{~cm}$ with a pedicle at the T8 dorsal nerve root exit (Figs. 2 and 3). Each cyst was meticulously dissected from the dura until a pedicle was identified. The pedicle was ligated using small metal clips and transected between clips (Fig. 2B). Thereafter, the cysts were freed and each was removed 


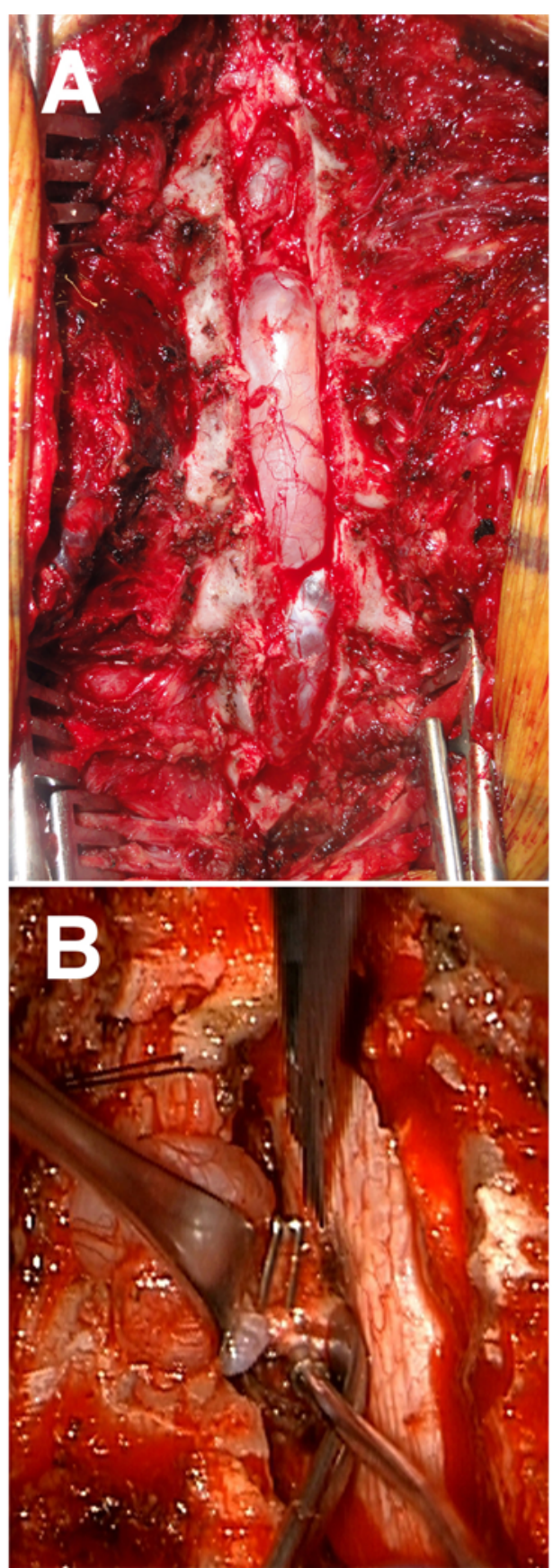

FIG. 2. Surgical operation for excision of SEACs. A: Following laminectomy, the extradural arachnoid cysts are observed. B: Mobilization of the caudal cyst demonstrates the pedicle communicating with the thecal sac. The pedicle was ligated with metal clips as shown, and subsequently transected. Figure is available in color online only.

en bloc. No neural elements were noted in the cysts. The pedicle stumps were then each oversewn with 4-0 Nurolon sutures to repair the dural defects in a watertight fashion, and subsequently covered with fibrin sealant. In this way, the cysts were completely removed and the thecal sac was not leaking CSF. The bone was replaced and secured with 4-mm titanium plates, and the wound was closed in layers.

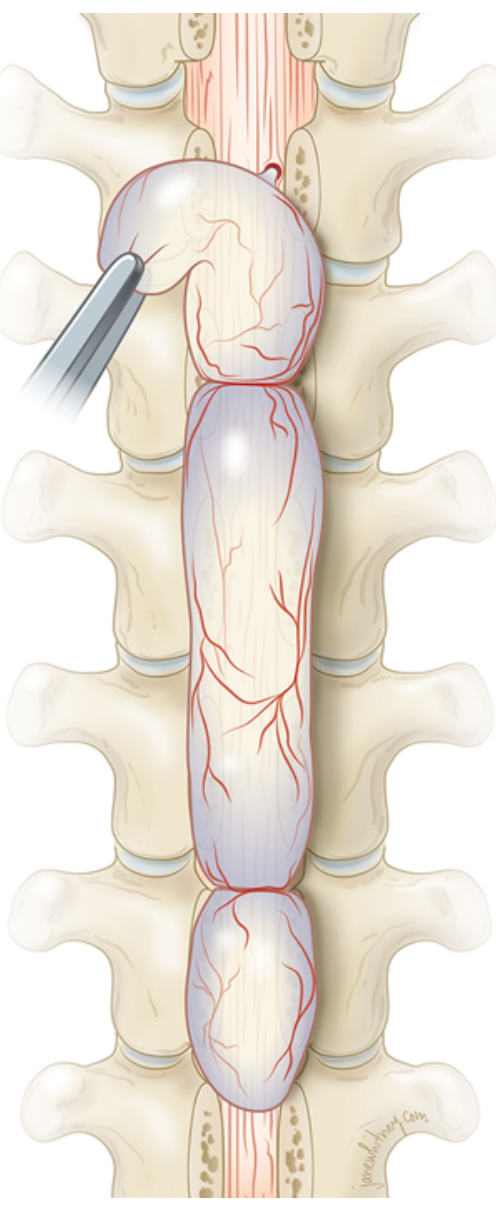

FIG. 3. Illustration of the exposure revealing 3 SEACs and demonstration of the attachment at the pedicle of the superior cyst. Copyright Jane Whitney. Published with permission. Figure is available in color online only.

\section{Postoperative Course}

In the immediate postoperative period, the patient's strength and sensation improved. Histological examination showed a thin, fluid-filled simple cyst lined with meningothelial cells, consistent with an arachnoid cyst. The patient continued to improve without recurrence but had a slightly exaggerated thoracic kyphosis and mild myelomalacia on repeat MRI at the 3-month follow-up (Fig. 4). Otherwise, his strength returned and he was independently ambulating without difficulty. At 1 year of follow-up, the patient's thoracic kyphosis progressed slightly. Otherwise, he denied pain or sensory complaints and reported normal strength and bowel/bladder function; a neurological examination showed no deficits. The patient was able to resume his normal life and refused further correction of his spinal deformity.

\section{Discussion}

Multiple SEACs are very rarely seen in children., ${ }^{9,23}$ Independently, arachnoid cysts are found incidentally in approximately $1.1 \%$ of the general adult population, the 


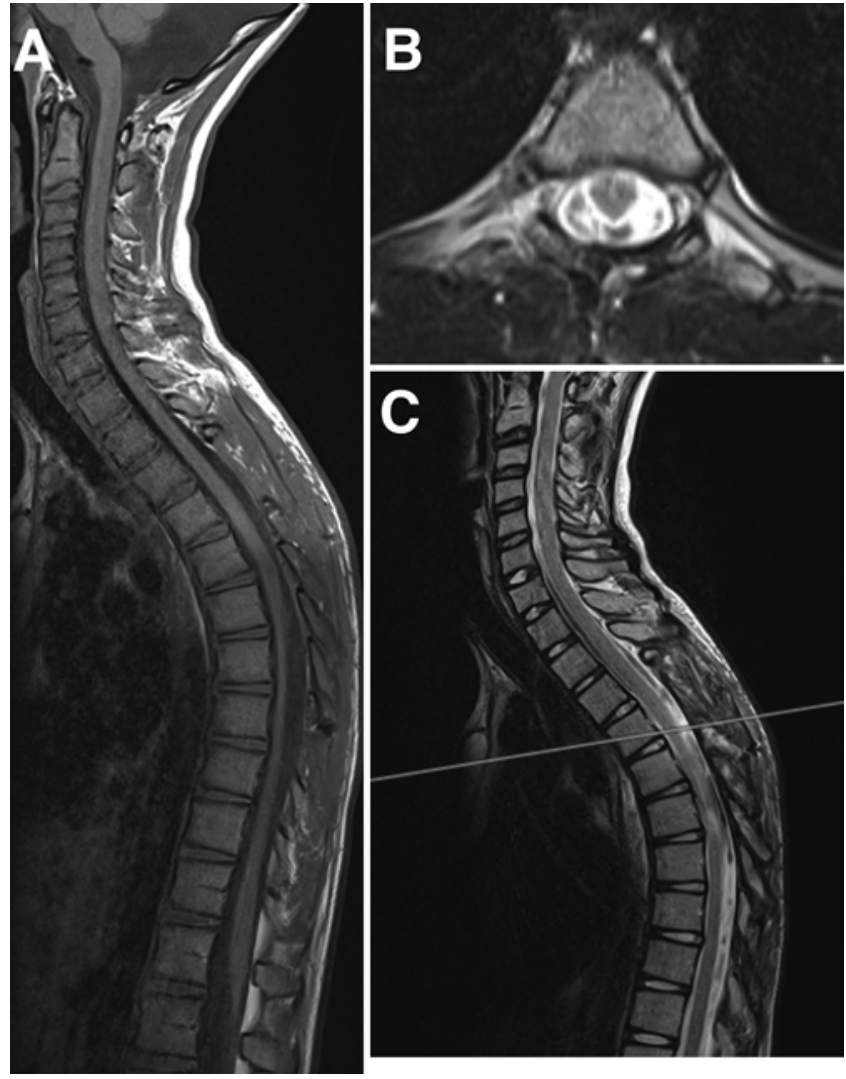

FIG. 4. Images obtained at the 3-month postoperative follow-up. A: Midsagittal T1-weighted MR image of the spine shows recurrence-free excision of the SEACs. B: Axial T2-weighted section at the level of T4-5 demonstrates resolution of the arachnoid cyst and consequent compression of the spinal cord. C: Midsagittal T2-weighted MR image of the spine shows the plane of panel B and spinal CSF flow as evidenced by flow voids in the spinal canal.

majority in the middle cranial fossa. ${ }^{39}$ Cavum septi pellucidi and cavum vergae are cystic dilatations of the potential space between the leaflets of the septum pellucidum that are designated based on their position relative to the foramina of Monro. These structures are physiological in the fetus, and typically involute by 3 months of age. ${ }^{37} \mathrm{In}$ adolescents and adults, the prevalence of cavum vergae approaches $1 \%-3 \%, 7,25,35$ These disease entities rarely cooccur, and to our knowledge our case is the first reported instance. In addition, the extreme forms-multiple large SEACs, a large retrocerebellar arachnoid cyst, and combined cavum septi pellucidi and cavum vergae-argue against the possibility that their co-occurrence is coincidental. Thus, while a single case report cannot definitively delineate causal relationships, we propose that a common cause links the findings in this patient.

The pathogenesis of SEAC, intracranial arachnoid cyst, and cavum vergae are incompletely understood. Persistence of the cavum vergae has been attributed to developmental defects of the corpus callosum or fornix (structures that are embryologically related to the septum pellucidum $)^{4,34}$ or impaired resorption of CSF by septal veins. ${ }^{36}$ Intracranial arachnoid cysts are believed to be formed by one-way flow into the cyst through communication with the subarachnoid space and active (fluid-producing cells) or passive (diffusion) transport of fluid into the cyst. ${ }^{1}$

To explain the pathogenesis of SEAC, the one-way flow theory posits that transient increases in CSF pressure force fluid into the cyst through its communication with the subarachnoid space..$^{15,22,27}$ Retrograde flow into the subarachnoid space can be prevented by occlusion at the narrow pedicle, even under a large pressure differential. One-way communication between the subarachnoid space and the cyst has occasionally been demonstrated intraoperatively ${ }^{18}$ or through myelography. ${ }^{17}$ Bulk flow of fluid through active or passive transport mechanisms into the cyst has also been proposed, but the homogeneity of the cyst fluid in comparison to CSF argues against these theories. ${ }^{1,20}$

Dural rents may be natural points of weakness in the dura, caused by the presence of arachnoid trabeculations that may proliferate abnormally ${ }^{17,31}$ or acquired etiologies, e.g., following neurosurgical procedures that violate the dura.$^{15}$ Alternatively, this case provides evidence for a congenital origin. A shared developmental etiology could at once explain the persistence of the cavum septi pellucidi and cavum vergae and the coexistence of multiple, spatially separated meningeal lesions. The finding of SEACs in lymphedema-distichiasis syndrome further corroborates the role of congenital abnormalities. This autosomal dominant disease, characterized by lower-extremity lymphedema, a double row of eyelashes (distichiasis), SEAC (often multiple), cardiac defects, and cleft palate, is caused by mutations in FOXC $2,{ }^{10}$ which encodes a transcription factor that is important in specification of paraxial cell fate..$^{40}$ Other genes involved in morphological patterning, such as HOXD4, have been linked with sporadic forms of SEAC..$^{28}$ Taken together, the genetic evidence, and association with other midline abnormalities such as neural tube defects, cleft palate, cavum septi pellucidi, and cavum vergae (in this case), suggests that perturbations in midline patterning play a role in SEAC pathogenesis.

The congenital origin theory also may explain the dorsal thoracic predilection of SEACs, which has previously been attributed to increased hydrostatic pressure from the CSF column..$^{20,27}$ Because the neural tube (and the spinal dura, derived from paraxial mesoderm) develops from ventral to dorsal, the dorsal midline appears to be particularly prone to maldevelopment. ${ }^{2}$ Having explained the dorsal preference, we attribute the thoracic location to the more anterior location of the spinal cord and the relative narrowing compared to the cervical and lumbar enlargements. Thus, the epidural potential space in the dorsal thoracic spinal column is greater and therefore provides more opportunity for cyst enlargement.

Ultimately, an understanding of the pathophysiology of SEACs will inform the optimal management. Asymptomatic cases may be managed conservatively as they appear to have an indolent natural history. ${ }^{30}$ Surgical treatment typically consists of two objectives: cyst excision and closure of the dural defect. We achieved good neurological outcome with complete excision of the cysts and repair of the pedicles. However, the patient developed postoperative kyphosis. This complication has been noted in most cases of multiple SEACs, ${ }^{18}$ perhaps due to the need for a 
multilevel laminectomy and a possible underlying connective tissue disorder. In some cases, cyst aspiration alone has been attempted, usually with rapid reaccumulation..$^{19,24}$ The relative importance of the two objectives has been debated; some argue that en bloc resection or excision of the cyst wall is sufficient (congruent with the theory of active transport), ${ }^{14,21}$ but in these cases the communication may have spontaneously closed. In other reports, recurrence can be frequent. ${ }^{18}$ Conversely, closure of the dural defect without complete resection (e.g., marsupialization or drainage, congruent with the theory of one-way flow) has yielded good outcome. 12,18,24,26 These latter approaches are particularly useful when the cyst is tightly adherent to the dura or extends across numerous spinal cord levels, confounding excision. Preoperative and endoscopic intraoperative identification of the dural defect followed by closure through a limited laminectomy may be associated with decreased postoperative kyphosis ${ }^{12,18}$ and is theoretically sufficient for resolution of the cyst. In this case, such an approach may have obviated an extensive laminoplasty and decreased the likelihood of postoperative kyphosis, but would have been challenging given multiple cysts whose sizes and relative positions were unclear preoperatively. Endoscopy has also proven useful in select cases, and has been used to identify the dural defect or to create a wide communication with the thecal sac for cyst fenestration. ${ }^{12,26}$ Cystoperitoneal shunting has been proposed in cases with large dural defects or recurrence as a final resort. ${ }^{16,30}$ The response of SEACs to these various treatments aligns with the need to correct the presumed origin of the cysts, i.e., the one-way valve mechanism at the cyst pedicle through a primary dural defect, paving the way for future development of less-invasive treatment options.

Diagnostic modalities may also play an important role in management of SEAC. Intraoperative neuromonitoring may have some utility in determining the severity of spinal compression and expected prognosis after treatment, ${ }^{6}$ but given the extradural location of an SEAC, the utility of these findings may be limited. Imaging follow-up is critical to identify recurrence or postoperative complications. Cyst reaccumulation is rare but typically occurs within months of surgery. ${ }^{18}$ In the pediatric population, kyphosis after laminectomy appears to occur within months to several years after surgery. ${ }^{41}$ Therefore, we recommend follow-up with MRI at 3 months and 1 year following surgery (to assess for cyst reaccumulation and kyphoscoliosis). Thereafter, plain radiographs may be used annually for surveillance of kyphoscoliosis.

We have demonstrated the unusual case of a child with multiple thoracic extradural arachnoid cysts associated with a retrocerebellar arachnoid cyst and cavum vergae. This case suggests that SEAC, at least in some instances, is a congenital midline abnormality, but additional reports will be needed for definitive association of these entities. Evaluation of the neuraxis for associated anomalies is warranted, particularly in those with atypical presentations (e.g., multiple cysts, large cysts, or family history).

\section{Acknowledgments}

We thank Ms. Jane Whitney for her work in illustration of Figure 3 in the manuscript.

\section{References}

1. Basaldella L, Orvieto E, Dei Tos AP, Della Barbera M, Valente M, Longatti P: Causes of arachnoid cyst development and expansion. Neurosurg Focus 22(2):E4, 2007

2. Beatriz N, Lopes S: Meninges: embryology, in Lee JH (ed): Meningiomas: Diagnosis, Treatment, and Outcome. London: Springer-Verlag, 2009, pp 25-29

3. Bergland RM: Congenital intraspinal extradural cyst. Report of three cases in one family. J Neurosurg 28:495-499, 1968

4. Bodensteiner JB, Schaefer GB: Wide cavum septum pellucidum: a marker of disturbed brain development. Pediatr Neurol 6:391-394, 1990

5. Brice G, Mansour S, Bell R, Collin JRO, Child AH, Brady $\mathrm{AF}$, et al: Analysis of the phenotypic abnormalities in lymphoedema-distichiasis syndrome in 74 patients with FOXC2 mutations or linkage to 16q24. J Med Genet 39:478-483, 2002

6. Chen JA, Coutin-Churchman PE, Nuwer MR, Lazareff JA: Suboccipital craniotomy for Chiari I results in evoked potential conduction changes. Surg Neurol Int 3:165, 2012

7. Chen JJ, Chen CJ, Chang HF, Chen DL, Hsu YC, Chang TP: Prevalence of cavum septum pellucidum and/or cavum Vergae in brain computed tomographies of Taiwanese. Acta Neurol Taiwan 23:49-54, 2014

8. Cloward RB, Bucy PC: Spinal extradural cyst and kyphosis dorsalis juvenilis. 1937. Surg Neurol 39:469-473, 1993

9. de Oliveira RS, Amato MCM, Santos MV, Simão GN, Machado HR: Extradural arachnoid cysts in children. Childs Nerv Syst 23:1233-1238, 2007

10. Fang J, Dagenais SL, Erickson RP, Arlt MF, Glynn MW, Gorski JL, et al: Mutations in FOXC2 (MFH-1), a forkhead family transcription factor, are responsible for the hereditary lymphedema-distichiasis syndrome. Am J Hum Genet 67:1382-1388, 2000

11. Fortuna A, La Torre E, Ciappetta P: Arachnoid diverticula: a unitary approach to spinal cysts communicating with the subarachnoid space. Acta Neurochir (Wien) 39:259-268, 1977

12. Funao H, Nakamura M, Hosogane N, Watanabe K, Tsuji $\mathrm{T}$, Ishii K, et al: Surgical treatment of spinal extradural arachnoid cysts in the thoracolumbar spine. Neurosurgery 71:278-284, 2012

13. Gortvai P: Extradural cysts of the spinal canal. J Neurol Neurosurg Psychiatry 26:223-230, 1963

14. Hatashita S, Kondo A, Shimizu T, Kurosu A, Ueno H: Spinal extradural arachnoid cyst-case report. Neurol Med Chir (Tokyo) 41:318-321, 2001

15. Hyndman OR, Gerber WF: Spinal extradural cysts, congenital and acquired; report of cases. J Neurosurg 3:474-486, 1946

16. Jensen F, Knudsen V, Troelsen S: Recurrent intraspinal arachnoid cyst treated with a shunt procedure. Acta Neurochir (Wien) 39:127-129, 1977

17. Lake PA, Minckler J, Scanlan RL: Spinal epidural cyst: theories of pathogenesis. Case report. J Neurosurg 40:774-778, 1974

18. Lee CH, Hyun SJ, Kim KJ, Jahng TA, Kim HJ: What is a reasonable surgical procedure for spinal extradural arachnoid cysts: is cyst removal mandatory? Eight consecutive cases and a review of the literature. Acta Neurochir (Wien) 154:1219-1227, 2012

19. Lin LC, Jason R: A rare case of spinal extradural arachnoid cyst with cord compression. Asian J Neurosurg 13:468470, 2018

20. Liu JK, Cole CD, Sherr GT, Kestle JRW, Walker ML: Noncommunicating spinal extradural arachnoid cyst causing spinal cord compression in a child. J Neurosurg 103 (3 Suppl):266-269, 2005 
21. Marbacher S, Barth A, Arnold M, Seiler RW: Multiple spinal extradural meningeal cysts presenting as acute paraplegia. Case report and review of the literature. J Neurosurg Spine 6:465-472, 2007

22. McCrum C, Williams B: Spinal extradural arachnoid pouches. Report of two cases. J Neurosurg 57:849-852, 1982

23. Myles LM, Gupta N, Armstrong D, Rutka JT: Multiple extradural arachnoid cysts as a cause of spinal cord compression in a child. Case report. J Neurosurg 91 (1 Suppl):116-120, 1999

24. Nabors MW, Pait TG, Byrd EB, Karim NO, Davis DO, Kobrine AI, et al: Updated assessment and current classification of spinal meningeal cysts. J Neurosurg 68:366-377, 1988

25. Nakano S, Hojo H, Kataoka K, Yamasaki S: Age related incidence of cavum septi pellucidi and cavum Vergae on CT scans of pediatric patients. J Comput Assist Tomogr 5:348349,1981

26. Neo M, Koyama T, Sakamoto T, Fujibayashi S, Nakamura T: Detection of a dural defect by cinematic magnetic resonance imaging and its selective closure as a treatment for a spinal extradural arachnoid cyst. Spine (Phila Pa 1976) 29:E426E430, 2004

27. O'Connell JEA: The cerebrospinal fluid pressure as an aetiological factor in the development of lesions affecting the central nervous system. Brain 76:279-298, 1953

28. Ogura Y, Miyake N, Kou I, Iida A, Nakajima M, Takeda K, et al: Identification of HOXD4 mutations in spinal extradural arachnoid cyst. PLoS One 10:e0142126, 2015

29. Park HY, Lee SH, Kim ES, Eoh W: Spinal extradural meningeal cyst and Scheuermann's disease: coincidence or causative factor? Childs Nerv Syst 28:1807-1810, 2012

30. Rabb CH, McComb JG, Raffel C, Kennedy JG: Spinal arachnoid cysts in the pediatric age group: an association with neural tube defects. J Neurosurg 77:369-372, 1992

31. Rexed BA, Wennström KG: Arachnoidal proliferation and cystic formation in the spinal nerve-root pouches of man. $\mathbf{J}$ Neurosurg 16:73-84, 1959

32. Roski RA, Rekate HL, Kurczynski TW, Kaufman B: Extradural meningeal cyst. Case report and review of the literature. Childs Brain 11:270-279, 1984

33. Sánchez-Carpintero R, Dominguez P, Núñez MT, PatiñoGarcía A: Spinal extradural arachnoid cysts in lymphedemadistichiasis syndrome. Genet Med 12:532-535, 2010
34. Sarwar M: The septum pellucidum: normal and abnormal. AJNR Am J Neuroradiol 10:989-1005, 1989

35. Schwidde JT: Incidence of cavum septi pellucidi and cavum Vergae in 1,032 human brains. AMA Arch Neurol Psychiatry 67:625-632, 1952

36. Sencer A, Sencer S, Turantan I, Devecioğlu O: Cerebrospinal fluid dynamics of the cava septi pellucidi and vergae. Case report. J Neurosurg 94:127-129, 2001

37. Shaw CM, Alvord EC Jr: Cava septi pellucidi et vergae: their normal and pathogical states. Brain 92:213-223, 1969

38. Tseng SH, Lin SM: Surgical treatment of thoracic arachnoiditis with multiple subarachnoid cysts caused by epidural anesthesia. Clin Neurol Neurosurg 99:256-258, 1997

39. Vernooij MW, Ikram MA, Tanghe HL, Vincent AJPE, Hofman A, Krestin GP, et al: Incidental findings on brain MRI in the general population. N Engl J Med 357:1821-1828, 2007

40. Wilm B, James RG, Schultheiss TM, Hogan BLM: The forkhead genes, Foxc1 and Foxc2, regulate paraxial versus intermediate mesoderm cell fate. Dev Biol 271:176-189, 2004

41. Yasuoka S, Peterson HA, MacCarty CS: Incidence of spinal column deformity after multilevel laminectomy in children and adults. J Neurosurg 57:441-445, 1982

\section{Disclosures}

The authors report no conflict of interest concerning the materials or methods used in this study or the findings specified in this paper.

\section{Author Contributions}

Conception and design: all authors. Acquisition of data: all authors. Analysis and interpretation of data: all authors. Drafting the article: all authors. Critically revising the article: all authors. Reviewed submitted version of manuscript: all authors. Approved the final version of the manuscript on behalf of all authors:

Cohen. Administrative/technical/material support: Cohen. Study supervision: Cohen.

\section{Correspondence}

Alan R. Cohen: The Johns Hopkins University School of Medicine, Baltimore, MD. alan.cohen@jhmi.edu. 